\title{
Comparison of Haemodynamic Effects of Levobupivacaine and Bupivacaine in Sub-arachnoid Block for Total Abdominal Hysterectomy
}

\author{
Mohammad Mizanoor Rahman ${ }^{* 1}$, Md. Ashraful Anam², Md. Mohim Ibn Sina ${ }^{3}$, \\ Md. Aminur Rahman ${ }^{4}$, Mohammad Nasir Uddin ${ }^{5}$, Mohammad Mahbubur Rahman ${ }^{6}$
}

\begin{abstract}
Introduction: Altered haemodynamics and arterial hypotension are the most prevalent untoward effects of sub-arachnoid block with bupivacaine. Use of levobupivacaine as pure $S(-)$ - enantiomer of bupivacaine has progressively increased due to its lower cardiotoxicity, neurotoxicity and shorter duration of motor block. This study aimed to compare the haemodynamic status of levobupivacaine and bupivacaine when used with fentanyl in Sub-arachnoid block (SAB) among patients undergone total abdominal hysterectomy. Materials and Methods: This randomized clinical trial enrolled 80 gynaecological patients scheduled for total abdominal hysterectomy under SAB. Forty patients were randomly assigned as trial group (levobupivacaine +fentanyl) and forty as control group (bupivacaine+fentanyl). Main outcome measures in both groups considered intraoperative haemodynamic stability (acute hypotension), cardiotoxicity (bradycardia or tachycardia) and time of administration of first dose of postoperative analgesics. Results: Bupivacaine caused comparatively more significant slowing of heart rate at 25 and 35 minutes of operation. Though no significant differences were found in systolic blood pressure between two groups, bupivacaine caused significant reduction of diastolic blood pressure in comparison to levobupivacaine at 6, 9, 45 minutes and at the end of surgery. Mean pressure found significantly lowered at 6 minutes and at the end of surgery following bupivacaine administration. The incidence of acute hypotension was significantly low in trial group and postoperative analgesia was maintained longer duration with levobupivacaine in control group. Conclusion: Levobupivacaine in comparison to bupivacaine showed more effective and satisfactory haemodynamic stability in sub-arachnoid block with less incidence of intraoperative acute hypotension and provides prolonged postoperative analgesic effect.

Keywords: Bupivacaine, Levobupivacaine, Sub-arachnoid block.

Number of Tables: 04; Number of References: 13; Number of Correspondence: 03.
\end{abstract}

*1. Corresponding Author:

Dr. Mohammad Mizanoor Rahman

Assistant Professor

Department of Anesthesiology

Institute of Child and Mother Health (ICMH), Dhaka.

E-mail: drmijan74@gmail.com

Mobile: +8801813590300 .

2. Dr. Md. Ashraful Anam

Assistant Professor

Department of Anesthesiology

Institute of Child and Mother Health (ICMH), Dhaka.

3. Dr. Md. Mohim Ibn Sina

FCPS Part-II Student

Department of Obs. \& Gynae

Bangabandhu Sheikh Mujib Medical University

(BSMMU), Dhaka.

4. Dr. Md. Aminur Rahman

Assistant Professor

Department of Anesthesiology

Institute of Child and Mother Health (ICMH), Dhaka.

5. Dr. Mohammad Nasir Uddin

Assistant Professor

Department of Pediatrics

Institute of Child and Mother Health (ICMH), Dhaka.

6. Dr. Mohammad Mahbubur Rahman

Registrar, Department of Pediatrics

Institute of Child and Mother Health (ICMH), Dhaka.
Introduction:

Sub-arachnoid block (SAB) or spinal anaesthesia is now-a-days a popular technique in gynaecological surgery including several advantages of rapid onset of profound anaesthesia, lower total drug dosages, and higher level of patient's satisfaction ${ }^{1,2}$. Level of sensorial blockade is one of the most important factors for successful anaesthesia and baricity is the most important one for local anaesthetic distribution ${ }^{3}$. Isobaric solutions remain in close proximity of injection site but hyperbaric solutions gravitate to the dependent areas. The duration of spinal anaesthesia is, therefore, related to dose and baricity of local anaesthetic administered ${ }^{3}$.

Bupivacaine is an amide local anaesthetic of hydrophilic nature with moderately rapid onset and long duration of action. Levobupivacaine is isobaric, and formulated by using normal saline as a diluent with specific gravity of 1000 at $37^{\circ} \mathrm{C}$ whereas bupivacaine heavy in $8 \%$ glucose is hyperbaric, having specific gravity of 1021 at $37^{\circ} \mathrm{C}^{4}$. Hyperbaric bupivacaine attains higher sensory levels of intrathecal anaesthesia in comparison to equal doses of isobaric levobupivacaine . $^{5}$ Both isobaric levobupivacaine and hyperbaric bupivacaine have been used for sub-arachnoid block with good results ${ }^{4}$.

Addition of opioids (fentanyl) with local anaesthetics for spinal anaesthesia is increasingly common both to enhance anaesthetic effect and to provide postoperative analgesia ${ }^{6}$. The dose of local anaesthetics can also be reduced by adding fentanyl. Small doses of opioids administered to the central nervous system not only provide adequate analgesia but also reduce the side effects of intravenous analgesics like pruritus, nausea and vomiting or respiratory depression? ${ }^{7}$. 
Cardiac toxicity; the most commonly encountered catastrophe, should be taken into immense consideration before selection of local anaesthetic agent. Hyperbaric bupivacaine solutions may cause hypotension or bradycardia after mobilization of anaesthetized patient but isobaric solutions are favored with respect to their less sensitivity to posture issues properties ${ }^{8}$. Levobupivacaine, being the $\mathrm{S}(-)$ enantiomer of bupivacaine, is less cardiotoxic due to its lower affinity to sodium channel and also less neurotoxic with shorter duration of motor block than hyperbaric bupivacaine. Thus its use has been increasing progressively ${ }^{9}$.

Though hyperbaric bupivacaine has satisfactory quality of analgesia following intrathecal administration, it regresses rapidly with more side effects. Isobaric levobupivacaine seems to provide a slow regression of analgesia with fewer undesirable haemodynamic effects except for its control of spread of analgesia ${ }^{10}$. But if the dosages as well as the speed of administration of isobaric solution are well adjusted, it is believed to be safe and reliable with an excellent level of analgesia for abdominal surgeries like hysterectomy.

This study was designed to compare the intraoperative haemodynamic effects of levobupivacaine and bupivacaine in spinal anaesthesia among patients undergone total abdominal hysterectomy. The study also compared postoperative analgesic effect by documenting the time of administration of first dose of analgesics in postoperative period.

\section{Materials and Methods:}

This randomized clinical trial was conducted in the Department of Anesthesiology of SSMC \& Mitford Hospital, Dhaka, from January 2015 to June 2015. Eighty gynaecological patients, aged 30-65 years with physical status-I \& II according to American Society of Anesthesiologists (ASA) scheduled for routine total abdominal hysterectomy under sub-arachnoid block were enrolled for the study. Patients with significant cardiac, pulmonary, hepatic or renal diseases, abnormal coagulation profile, spinal deformities, evidences of skin infection at the site of injection, disabling neuropsychiatric disorders, known hypersensitivity to bupivacaine, levobupivacaine or fentanyl, chronic drug abusers and alcoholics were excluded from this study. Forty patients were randomly assigned for isobaric levobupivacaine designated as "trial group" and forty for hyperbaric bupivacaine designated as "control group". Baseline heart rates, systolic, diastolic and mean arterial blood pressures (MAP) were recorded preoperatively. Patients in "trial group" received $0.5 \%$ levobupivacaine $15 \mathrm{mg}(3 \mathrm{ml})$ + 25 microgram fentanyl $(0.5 \mathrm{ml})$ (total volume $3.5 \mathrm{ml})$ and "control group" received $0.5 \%$ bupivacaine heavy $15 \mathrm{mg}$ (3 $\mathrm{ml})+25$ microgram fentanyl $(0.5 \mathrm{ml})$ (total volume $3.5 \mathrm{ml})$ slowly at a rate of $1 \mathrm{ml} / 5 \mathrm{sec}$ in subarachnoid space at L3-L4 or L4-L5 level. Each patient was immediately turned to supine position. After intrathecal injection, heart rate, non-invasive systolic, diastolic and mean arterial blood pressures were recorded at every 3 minutes for 15 minutes, thereafter at every 10 minutes up to 45 minutes and at the end of surgery. The time when first dose of postoperative analgesic required was determined in each patient. Acute hypotension was defined as decrease in mean arterial blood pressure more than $20-30 \%$ from baseline, bradycardia as heart rate less than 45 beats/min and tachycardia as heart rate more than 100 beats $/ \mathrm{min}$. All data were recorded in a structured questionnaire by an anesthesiologist involved.

\section{Results:}

Mean age of study patients was $45.6 \pm 7.1$ and $44.9 \pm 5.2$ years in trial \& control group respectively. Heart rate, systolic, diastolic and MAP were almost homogenously distributed between two groups at baseline with no significant differences (Table I). Bupivacaine caused comparatively more significant slowing of heart rate at 25 and 35 minutes (Table II). Though no significant $(p>0.05)$ differences were found in systolic blood pressure between two groups, bupivacaine caused significant $(p<0.05)$ reduction of diastolic blood pressure in comparison to levobupivacaine at 6, 9, 45 minutes and at the end of surgery (Table III). Mean arterial pressure also significantly $(\mathrm{p}<0.05)$ lowered at 6 minutes and at the end of surgery following bupivacaine administration (Table III). The incidence of acute hypotension was significantly $(\mathrm{p}<0.05)$ low in trial group than control group $(27.5 \%$ vs. $50.0 \%)$. Postoperative analgesia was maintained longer duration with levobupivacaine in control group as time of postoperative 1st dose analgesic requirement was significantly later (Table IV).

Table-I: Baseline haemodynamic parameters of study population.

\begin{tabular}{lccc}
\hline Baseline parameters & Trial group & Control group & p value \\
\hline Heart rate (beats/min) & $93.0 \pm 17.1$ & $95.2 \pm 15.5$ & 0.479 \\
Systolic blood pressure $(\mathrm{mmHg})$ & $139.4 \pm 20.4$ & $134.1 \pm 16.4$ & 0.201 \\
Diastolic blood pressure $(\mathrm{mmHg})$ & $84.6 \pm 11.6$ & $81.9 \pm 11.4$ & 0.306 \\
Mean arterial pressure $(\mathrm{mmHg})$ & $100.1 \pm 18.4$ & $101.1 \pm 15.1$ & 0.786 \\
\hline
\end{tabular}

Values expressed as Mean \pm standard deviation, $\mathrm{p}$ value was obtained by Chi-square test.

Table-II: Comparison of heart rate at different time interval.

\begin{tabular}{lccc}
\hline Heart rate (beats/min) & Trial group & Control group & p value \\
\hline At 3 minutes & $94.0 \pm 22.0$ & $92.0 \pm 16.0$ & 0.654 \\
At 6 minutes & $91.0 \pm 21.0$ & $85.0 \pm 15.0$ & 0.151 \\
At 9 minutes & $85.0 \pm 19.0$ & $90.0 \pm 13.0$ & 0.242 \\
At 12 minutes & $82.0 \pm 17.0$ & $78.0 \pm 11.0$ & 0.193 \\
At 15 minutes & $81.0 \pm 15.0$ & $76.0 \pm 10.0$ & 0.078 \\
At 25 minutes & $80.0 \pm 14.0$ & $73.0 \pm 9.0$ & $\mathbf{0 . 0 1 3}$ \\
At 35 minutes & $77.0 \pm 13.0$ & $71.0 \pm 8.0$ & $\mathbf{0 . 0 3 2}$ \\
At 45 minutes & $76.0 \pm 14.0$ & $73.0 \pm 10.0$ & 0.162 \\
At the end of surgery & $79.0 \pm 15.0$ & $76.0 \pm 12.0$ & 0.264 \\
\hline
\end{tabular}

*Values expressed as Mean \pm standard deviation, $\mathrm{p}$ value was obtained by Chi-square test. 
Table-III: Comparison of systolic, diastolic and mean arterial pressure at different time interval.

\begin{tabular}{|c|c|c|c|c|c|c|c|c|c|}
\hline \multirow[t]{2}{*}{ Variables } & \multicolumn{2}{|c|}{ Systolic BP } & \multirow{2}{*}{$\mathrm{p}$ value } & \multicolumn{2}{|c|}{ Diastolic BP } & \multirow[t]{2}{*}{$p$ value } & \multicolumn{2}{|c|}{ Mean pressure } & \multirow{2}{*}{ p value } \\
\hline & $\begin{array}{c}\text { Trial } \\
\text { group }\end{array}$ & $\begin{array}{c}\text { Control } \\
\text { group }\end{array}$ & & $\begin{array}{c}\text { Trial } \\
\text { group }\end{array}$ & $\begin{array}{l}\text { Control } \\
\text { group }\end{array}$ & & $\begin{array}{c}\text { Trial } \\
\text { group }\end{array}$ & $\begin{array}{c}\text { Control } \\
\text { group }\end{array}$ & \\
\hline At 3 minutes & $\begin{array}{c}120.6 \pm \\
23.0\end{array}$ & $\begin{array}{c}115.4 \pm \\
15.8\end{array}$ & 0.241 & $\begin{array}{c}73.8 \pm \\
16.2\end{array}$ & $\begin{array}{c}69.9 \pm \\
13.1\end{array}$ & 0.231 & $\begin{array}{c}87.2 \pm \\
18.6\end{array}$ & $\begin{array}{c}82.7 \pm \\
13.0\end{array}$ & 0.203 \\
\hline At 6 minutes & $\begin{array}{c}116.2 \pm \\
24.6\end{array}$ & $\begin{array}{c}106.9 \pm \\
16.1\end{array}$ & 0.052 & $\begin{array}{c}69.5 \pm \\
16.0\end{array}$ & $\begin{array}{c}63.1 \pm \\
13.9\end{array}$ & 0.035 & $\begin{array}{c}85.0 \pm \\
20.0\end{array}$ & $\begin{array}{c}76.4 \pm \\
14.1\end{array}$ & 0.029 \\
\hline At 9 minutes & $\begin{array}{c}110.3 \pm \\
23.1\end{array}$ & $\begin{array}{c}104.9 \pm \\
16.0\end{array}$ & 0.230 & $\begin{array}{c}67.0 \pm \\
14.4\end{array}$ & $\begin{array}{c}60.8 \pm \\
12.8\end{array}$ & 0.047 & $\begin{array}{c}79.1 \pm \\
18.2\end{array}$ & $\begin{array}{c}74.7 \pm \\
14.5\end{array}$ & 0.235 \\
\hline At 12 minutes & $\begin{array}{c}108.1 \pm \\
20.9\end{array}$ & $\begin{array}{c}102.2 \pm \\
14.8\end{array}$ & 0.145 & $\begin{array}{c}64.6 \pm \\
15.3\end{array}$ & $\begin{array}{c}60.9 \pm \\
12.6\end{array}$ & 0.239 & $\begin{array}{c}77.9 \pm \\
17.3\end{array}$ & $\begin{array}{c}73.3 \pm \\
14.3\end{array}$ & 0.199 \\
\hline At 15 minutes & $\begin{array}{c}106.9 \pm \\
19.6\end{array}$ & $\begin{array}{c}103.7 \pm \\
17.8\end{array}$ & 0.437 & $\begin{array}{c}66.1 \pm \\
15.6\end{array}$ & $\begin{array}{c}62.6 \pm \\
12.9\end{array}$ & 0.271 & $\begin{array}{c}76.2 \pm \\
14.0\end{array}$ & $\begin{array}{c}73.1 \pm \\
14.9\end{array}$ & 0.342 \\
\hline At 25 minutes & $\begin{array}{l}100.4 \pm \\
12.4\end{array}$ & $\begin{array}{c}99.0 \pm \\
15.5\end{array}$ & 0.668 & $\begin{array}{c}59.6 \pm \\
11.8\end{array}$ & $\begin{array}{c}57.1 \pm \\
12.0\end{array}$ & 0.342 & $\begin{array}{c}70.7 \pm \\
12.6\end{array}$ & $\begin{array}{c}70.8 \pm \\
13.9\end{array}$ & 0.993 \\
\hline At 35 minutes & $\begin{array}{l}98.0 \pm \\
12.0\end{array}$ & $\begin{array}{c}96.7 \pm \\
13.1\end{array}$ & 0.698 & $\begin{array}{c}60.0 \pm \\
11.9\end{array}$ & $\begin{array}{c}56.9 \pm \\
11.4\end{array}$ & 0.282 & $\begin{array}{c}69.2 \pm \\
10.3\end{array}$ & $\begin{array}{c}68.5 \pm \\
12.3\end{array}$ & 0.776 \\
\hline At 45 minutes & $\begin{array}{c}99.4 \pm \\
12.6\end{array}$ & $\begin{array}{c}97.4 \pm \\
12.5\end{array}$ & 0.484 & $\begin{array}{c}61.9 \pm \\
13.3\end{array}$ & $\begin{array}{c}56.7 \pm \\
9.8\end{array}$ & 0.043 & $\begin{array}{c}72.3 \pm \\
12.4\end{array}$ & $\begin{array}{c}67.6 \pm \\
10.8\end{array}$ & 0.072 \\
\hline At end of surgery & $\begin{array}{c}102.5 \pm \\
15.0\end{array}$ & $\begin{array}{c}100.3 \pm \\
10.6\end{array}$ & 0.439 & $\begin{array}{c}63.8 \pm \\
11.5\end{array}$ & $\begin{array}{c}58.6 \pm \\
8.3\end{array}$ & 0.022 & $\begin{array}{c}75.8 \pm \\
13.3\end{array}$ & $\begin{array}{c}70.8 \pm \\
8.9\end{array}$ & 0.050 \\
\hline
\end{tabular}

*Values expressed as Mean \pm standard deviation, $p$ value was obtained by Chi-square test.

Table-IV: Per-operative complications encountered and requirement of postoperative analgesic.

\begin{tabular}{lccc}
\hline Variables* & $\begin{array}{c}\text { Trial group } \\
(\mathbf{n}=\mathbf{4 0})\end{array}$ & $\begin{array}{c}\text { Control group } \\
(\mathbf{n}=40)\end{array}$ & p value \\
\hline Bradycardia $(<45$ beats $/ \mathrm{min})$ & $2(5.0)$ & $1(2.5)$ & $0.50 \dagger$ \\
Tachycardia $(>100$ beats $/ \mathrm{min})$ & $6(15.0)$ & $5(12.5)$ & $0.745 \dagger$ \\
Acute hypotension & $11(27.5)$ & $20(50.0)$ & $0.039 \dagger$ \\
Time of postoperative & $233.0 \pm 20.0$ & $161.4 \pm 24.5$ & $<0.05 \dagger$ \\
analgesic requirement $(\min )$ & & & \\
\hline
\end{tabular}

*Values : Expressed as numbers (n) and percentages (\%) in parentheses or Mean $\pm \mathrm{SD}$

tp value: Obtained by Chi-square test

$\ddagger p$ value: Obtained by Student's t-test

\section{Discussion:}

The goal of this study was to compare the intraoperative haemodynamic effects of levobupivacaine and bupivacaine when used with fentanyl in SAB for TAH. Forty patients were randomly assigned for levobupivacaine + fentanyl (trial group) and 40 for bupivacaine + fentanyl (control group). Intraoperative haemodynamic parameters including heart rate, systolic, diastolic and mean pressure were recorded at different time interval.

Following SAB, heart rate decreased insidiously from baseline to 35 minutes in both groups but bupivacaine caused comparatively more significant slowing of heart rate at 25 and 35 minutes. Fattorini et al. showed that levobupivacaine and bupivacaine decreased heart rate over 30 minutes after anesthesia in major orthopedic surgery without significant inter group differences ${ }^{11}$. Systolic and diastolic BP in both study groups exhibited a sharp fall at 3-6 minute of intervention. Thereafter the fall of systolic BP was insidious up to 35 minutes and became stable at the end of surgery without significant differences between study groups. Conversely, the fall of diastolic BP was slow and steady up to 12 minutes with another sharp fall at 25 minutes and stabilized at the end. Though in this study bupivacaine caused comparatively significant reduction of diastolic BP than levobupivacaine at 6, 9, 45 minutes and at the end of surgery, no significant inter group differences of systolic and diastolic BP were noted by Fattorini et al. ${ }^{11}$ In another prospective observational study, Herrera et al. found a decrease $(\mathrm{p}<0.05)$ in systolic and diastolic BP at 30 minutes intraoperatively ${ }^{12}$. This study also found significantly lowered mean arterial pressure (MAP) at 6 minutes and at the end of surgery following bupivacaine administration. But no inter group difference in MAP was observed by Fattorini et al. ${ }^{11}$ Contrary to this study Guler et al. found bradycardia more common in bupivacaine fentanyl group. The incidence of acute hypotension was significantly $(p<0.05)$ low in trial group (levobupivacaine) than control group (bupivacaine) $(27.5 \%$ vs. $50.0 \%)$. This findings support several other studies ${ }^{12,13}$. Though bupivacaine heavy yields satisfactory quality of analgesia following 
$\mathrm{SAB}$, it regresses rapidly ${ }^{10}$. Postoperative analgesia was maintained longer duration with levobupivacaine in this study. Erdil et al. similarly showed isobaric levobupivacaine provides a slow regression of analgesia ${ }^{10}$. Guler et al. also concluded that the time of first analgesic requirement was earlier in group bupivacaine compared to levobupivacaine $^{13}$.

\section{Conclusion:}

Levobupivacaine when co-administered with fentanyl in SAB maintains intraoperative haemodynamic stability better than the bupivacaine-fentanyl combination. The incidence of acute intraoperative hypotension is appreciably reduced and duration of postoperative analgesia also becomes prolonged following levobupivacaine administration.

\section{Recommendation}

Intrathecal levobupivacaine-fentanyl combination could be an effective and reliable alternative to bupivacaine-fentanyl combination in patients undergoing total abdominal hysterectomy under sub-arachnoid block.

\section{Conflict of Interest: None.}

\section{Acknowledgement:}

The authors would like to thank all participating patients for taking part in this study. We are greatly indebted to the institutional anesthetist group, Post Anesthetic Care Unit staff and Gynaecological team for their endless support.

\section{References:}

1. Velde MV, Teunkens A, Hanssens M. Intrathecal sufentanil and fetal heart rate abnormalities: a double-blind, double placebo-controlled trial comparing two forms of combined spinal epidural analgesia with epidural analgesia in labor. Anesth Analg. 2004; 98: 1153-59.

https://doi.org/10.1213/01.ANE.0000101980.34587.66

PMid: 15041616

2. Nakamura G, Ganem EM. Effects on mother and fetus of epidural and combined spinal-epidural techniques for labor analgesia. Rev Assoc Med Bras. 2009; 55: 405-09.

https://doi.org/10.1590/S0104-42302009000400014

PMid:19750306

3. Akbay KB, Boztepe A, Sezen YG. A comparison of bupivacaine solutions with or without fentanyl intrathecally Türkiye Klinikleri. J Med Sci. 2007; 5: 118-23.

4. Kokki H, Tuovinen K, Hendolin H. Spinal anesthesia for paediatric day-case surgery: a double-blind, randomized, parallel group, prospective comparison of isobaric and hyperbaric bupivacaine. Br J Anaesth. 1998; 81: 502-06.

https://doi.org/10.1093/bja/81.4.502

PMid:9924220
5. Hallworth SP, Fernando R, Columb MO, Stocks GM. The Effect of Posture and Baricity on the Spread of Intrathecal Bupivacaine for Elective Cesarean Delivery. Anesthesia \& Analgesia. 2005; 100(4): 1159-1165.

https://doi.org/10.1213/01.ANE.0000149548.88029.A2

PMid: 15781538

6. Parlow JL, Money P, Chan P. Addition of opioids alters the density and spread of intrathecal local anesthetics? An in vitro study. Can J Anesth. 1999; 46: 66-70.

https://doi.org/10.1007/BF03012518

PMid:10078407

7. Santos LM, Santos VCJ. Intrathecal morphine plus general anesthesia in cardiac surgery: effects on pulmonary function, postoperative analgesia and plasma morphine concentration. Clinics. 2009; 64: 279-85.

https://doi.org/10.1590/S1807-59322009000400003

PMid:19488583 PMCid:PMC2694465

8. Povey HMR, Jacobsen J, Westergaard-Nielsen J. Subarachnoid Analgesia with Hyperbaric 0.5\% Bupivacaine: Effect of a 60-Min Period of Sitting. Acta Anaesthesio- logica Scandinavica. 1989; 33(4): 295-297.

https://doi.org/10.1111/j.1399-6576.1989.tb02911.x

PMid:2655366

9. Panula J, Pihlajamaki H, Mattila VM. Mortality and cause of death in hip fracture patients aged 65 or older: a population-based study. BMCm Musculoskelet Disor. 2011: 12.

https://doi.org/10.1186/1471-2474-12-105

PMCid:PMC3118151

10. Erdil F, Bulut S, Demirbilek S. The effects of intrathecal levobupivacaine and bupivacaine in the elderly. Anaesthesia. 2009; 64: 942-46.

https://doi.org/10.1111/j.1365-2044.2009.05995.x

PMid:19686477

11. Fattorini F, Ricci Z, Rocco A. Levobupivacaine versus racemic bupivacaine for spinal anaesthesia in orthopedic major surgery. Minerva Anestesiol. 2006; 72: 637-44.

12. Herrera R, Andres J, Estan L, Olivas FJM, Martínez-Mir I and Steinfeldt T. Haemodynamic impact of isobaric levobupivacaine versus hyperbaric bupivacaine for subarachnoid anesthesia in patients aged 65 and older undergoing hip surgery. BMC Anesthesiology. 2014; 14: 97.

https://doi.org/10.1186/1471-2253-14-97

PMid:25371654 PMCid:PMC4218988

13. Guler G, Cakir G, Ulgey A, Ugur F, Bicer C, Gunes I, et al. A Comparison of Spinal Anesthesia with Levobupivacaine and Hyperbaric Bupivacaine for Cesarean Sections: A Randomized Trial. Open J Anesthesiol. 2012; 2: 84-89.

https://doi.org/10.4236/ojanes.2012.23020 